\title{
The pathology of parietal pleural plaques
}

\author{
G. HEFIN ROBERTS
}

From the Pathology Department, Southern General Hospital, Glasgow

SYNOPSIS The incidence, morbid anatomy, histology, and relationship of hyaline pleural plaquesto exposure to asbestos has been studied.

Plaques were found in $12.3 \%$ of 334 hospital necropsies (in an urban population in Glasgow, 41 cases). In $85.3 \%$ (35 cases) asbestos bodies were found in the lungs. There is evidence of a dose-i response relationship between the number of asbestos bodies found in the lungs and the presence $e_{+}^{+}$ of pleural plaques.

The selective distribution of plaques within the pleural cavities suggests that mechanical factors 0 play a part in their localization.

Histological examination contributed little to understanding the mechanism of plaque formation:that asbestos bodies have been detected in only a few cases suggest that their presence in the parietal pleura is not essential to plaque formation. The suggested mechanisms of plaque formation are discussed.

In the earlier literature on asbestosis there is reference to changes in pleural cavities (Cooke, 1927; Oliver, 1927; Stewart, Tattersall, and Haddow, 1932; Gloyne, 1933 and 1935; Lynch and Smith, 1935; Wyers, 1949) but in most reports it is difficult to be certain whether the changes described refer to the parietal or visceral pleura; in cases with fibrous obliteration of the cavities, distinction between the two layers is often difficult.

It is now believed that there is a relationship between hyaline plaque formation on the parietal pleura and exposure to asbestos unaccompanied by pulmonary fibrosis (asbestosis) (Kiviluoto, 1960; Meurmann, 1966). The epidemiological value of radiology in detecting plaques to assess the extent of exposure to asbestos in a community has been shown by several workers (Hourihane, Lessof, and Richardson, 1966; Kiviluoto, 1960; Anton, 1968).

Pathological studies are, however, few (Hourihane et al, 1966; Meurmann, 1966), and in most of the 'community studies' on the incidence of asbestos bodies in routine hospital necropsies, pleural plaques are not mentioned (Thomson, Kaschula, and Macdonald, 1963; Cauna, Totteun, and Gross, 1965; Anjilvel and Thurlbeck, 1966; Thomson and Graves, 1966; Ashcroft, 1968).

In a study of the incidence of asbestos bodies in hospital necropsies in Glasgow (Roberts, 1969) asbestos bodies were found in 123 of 400 consecutive Received for publication 3 September 1970. necropsies $(30.8 \%)$; the pleural cavities were per-sonally examined for plaques in 334 cases. This papero presents my findings on the incidence, morbido anatomy, histology, and relationship of pleura $\rho$ plaques to asbestos bodies in the lungs.

\section{Methods and Materials}

The necropsies were performed in the pathology department of a general hospital serving a population: of approximately 250,000 in south-west Glasgow This is a heavily industrialized urban population close to the Clyde with its concentration of heavys industry, in particular shipbuilding.

The pleural cavities of 334 cases were examined for hyaline plaques, except for the plaques from 130 cases found in the first 100 necropsies (Roberts 1967). Whether plaques were unilateral or bilaterab and their sites in the pleural cavities was noted; now distinction was made between calcified and non+ calcified plaques. The diaphragm and pericardial sac $c_{-}$ were also examined and the presence or absence of fibrous pleural adhesions noted.

The histology of the plaques was studied in 28 cases and asbestos bodies looked for in $5 \mu$ and $25 \mu$ thick sections, and also by Gold and Kerr's extraction technique (1967). In these 28 cases random sectionsD of the basal segments of both lower lobes, which? included the visceral pleura, were also available.

Thick smears from the basal segments of botk 
lower lobes were made at necropsy and examined for asbestos bodies; 300 consecutive low-power fields (16 mm objective) were examined from each slide and asbestos bodies counted (Roberts, 1967 and 1969).

In none of the cases was a detailed occupational history available, but a note was made of the patient's present or last known occupation when available in the clinical notes.

\section{Results}

Hyaline pleural plaques were found in 41 of 334 $(12.3 \%)$ necropsies (Table I). The highest incidence of plaques was found in the seventh decade (21 cases, $51 \cdot 2 \%$ ); this is the age group which also showed the highest incidence of asbestos bodies in the $\mathbf{4 0 0}$ necropsies (39.4\% of 142 cases, $58.1 \%$ of 86 males). Only once were plaques seen in a female (case 27). In 35 of the 41 cases $(85.3 \%)$ asbestos bodies were

\begin{tabular}{|c|c|c|c|c|}
\hline $\begin{array}{l}\text { Case } \\
\text { No. }\end{array}$ & Sex & $\begin{array}{l}\text { Age } \\
\text { (yr) }\end{array}$ & Occupation & $\begin{array}{l}\text { Asbestos } \\
\text { Bodies } \\
\text { per } 600 \text { lpf }\end{array}$ \\
\hline 1 & $\mathbf{m}$ & 62 & Riveter (shipyard) & 6 \\
\hline 2 & $\mathbf{m}$ & 46 & Joiner (shipyard) & 50 \\
\hline 3 & $\mathbf{m}$ & 84 & Retired engineer & 6 \\
\hline 4 & $\mathbf{m}$ & 78 & Retired engineer & 2 \\
\hline 5 & $\mathbf{m}$ & 74 & Riveter (shipyard) & 430 \\
\hline 6 & $\mathrm{~m}$ & 63 & Coppersmith & 18 \\
\hline 7 & $\mathbf{m}$ & 48 & Baker & 0 \\
\hline 8 & $\mathbf{m}$ & 61 & Joiner & 112 \\
\hline 9 & $\mathrm{~m}$ & 74 & Turner & 3 \\
\hline 10 & m & 65 & $?$ & 73 \\
\hline 11 & $\mathbf{m}$ & 65 & Shipwright & 0 \\
\hline 12 & $\mathbf{m}$ & 57 & $?$ & 357 \\
\hline 13 & $\mathrm{~m}$ & 67 & Dock wat:hman & 4 \\
\hline 14 & m & 63 & Plater (shipyard) & 168 \\
\hline 15 & $\mathrm{~m}$ & 67 & Labourer & 30 \\
\hline 16 & $\mathbf{m}$ & 76 & Retired riveter (shipyard) & 46 \\
\hline 17 & $\mathbf{m}$ & 65 & Shipwright & 9 \\
\hline 18 & m & 63 & Asphalter & 2 \\
\hline 19 & $\mathrm{~m}$ & 82 & Retired electrician & 15 \\
\hline 20 & $\mathbf{m}$ & 67 & Boiler maker (shipyard) & 42 \\
\hline 21 & $\mathrm{~m}$ & 71 & Retired boiler maker & 19 \\
\hline 22 & $\mathbf{m}$ & 59 & Riveter (shipyard) & 1 \\
\hline 23 & m & 83 & Retired riveter (shipyard) & 5 \\
\hline 24 & $\mathbf{m}$ & 65 & ? & 27 \\
\hline 25 & $\mathrm{~m}$ & 67 & $?$ & 22 \\
\hline 26 & $\mathbf{m}$ & 44 & Sheet iron worker & 33 \\
\hline 27 & f & 68 & Retired factory worker & 1 \\
\hline 28 & $\mathbf{m}$ & 47 & Dock foreman & 3 \\
\hline 29 & $\mathbf{m}$ & 77 & ? & 0 \\
\hline 30 & $\mathbf{m}$ & 53 & Storeman & 843 \\
\hline 31 & $\mathbf{m}$ & 63 & Shipyard worker & 6 \\
\hline 32 & $\mathbf{m}$ & 57 & Elestrician & 24 \\
\hline 33 & $\mathbf{m}$ & 45 & Driller & 0 \\
\hline 34 & $\mathbf{m}$ & 76 & Metal pickler & 0 \\
\hline 35 & $\mathrm{~m}$ & 64 & ? & 1064 \\
\hline 36 & $\mathrm{~m}$ & 62 & Coppersmith & 32 \\
\hline 37 & $\mathbf{m}$ & 66 & Blacksmith & 1 \\
\hline 38 & m & 67 & Labourer & 284 \\
\hline 39 & $\mathbf{m}$ & 71 & Retired engineer & 0 \\
\hline 40 & $\mathbf{m}$ & 63 & ? & 4 \\
\hline 41 & $\mathbf{m}$ & 61 & Joiner (shipyard) & 590 \\
\hline
\end{tabular}

Table I Details of 41 cases of pleural plaques found in the basal smears; plaques were present in six cases without bodies being found in the smears $(14.7 \%)$. This difference is statistically significant $\left(\chi^{2}=22.0, \mathrm{P}<0.001\right)$.

In 57 cases in which fewer than five bodies were counted plaques were found in nine $(15.8 \%)$ while in 52 cases with five to 50 bodies, $32.6 \%$ (17 cases) showed plaques. In eight cases in which more than 100 bodies were found plaques were present in all. There was one example of classical asbestosis and the lungs of this case showed bilateral plaques as did those of one of two cases of pleural mesothelioma.

\section{Occupation}

The occupations were mentioned in the clinical notes in $\mathbf{3 3}$ of the $\mathbf{4 0}$ males in whom plaques were found. In 13 the shipyards were specifically mentioned as the place of work (riveter, joiner, shipwright, plater, boilermaker, dock foreman). Other occupations mentioned were engineer, coppersmith, labourer, electrician, driller. Further occupational details would undoubtedly have revealed a higher proportion of shipyard workers.

\section{Pathology of Pleural Plaques}

\section{MACROSCOPIC}

Parietal pleural plaques occurred as discrete, raised, irregularly shaped areas, separated either by normal or slightly thickened pleura. The thinner plaques were only slightly raised above the pleural surface; they were smooth and of a greyish-white colour. The thicker plaques were ivory white or cream coloured; they were either smooth or showed a fine or coarse nodularity. They varied in size from a few millimetres to 10 centimetres.

Plaques on the costal pleura could easily be stripped away from the intercostal muscles; plaques on the diaphragm were firmly adherent and could not be removed from the underlying tendon. Most of the plaques had a leathery consistency and when removed from the body could be bent; others more heavily calcified were brittle and fractured easily.

Plaques were most commonly found on the posterior wall of the lower half of the pleural spaces, those in the intercostal space tended to have an elliptical shape and ran parallel to the ribs above and below. No plaques were found at the apices of the pleural cavities, in the costophrenic angles, or on the anterior wall close to the costochondral junction.

In 28 cases the distribution of the plaques was noted. In 10 cases the plaques were unilateral (left 6 , right 4), asbestos bodies being found in the basal smears in nine $(90 \%)$. In two cases where plaques were found in the left pleura the right pleuralspace 


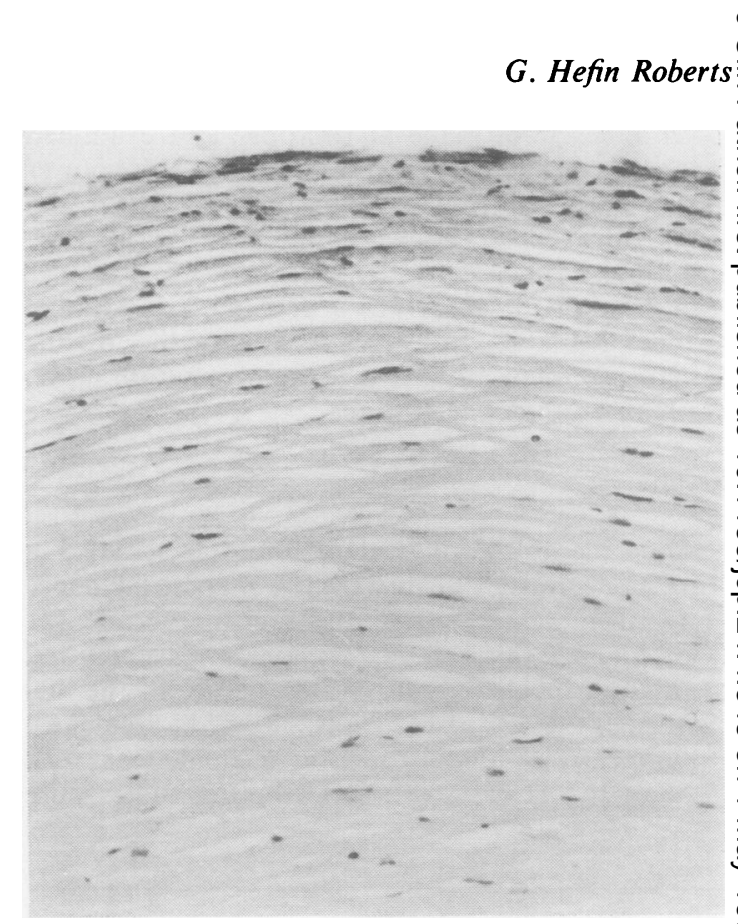

was obliterated by fibrous adhesions. In 18 cases bilateral plaques were found, asbestos bodies being found in the smears of $15(82.1 \%)$; in one case plaques were found on both halves of the diaphragm and in the left pleura, the right pleural space being obliterated by fibrous adhesions.

\section{HISTOLOG Y}

Plaques from 28 cases were sectioned. All were composed of slightly undulating dense bands of avascular collagen, lying parallel to the surface and in places showing a finely reticulated meshwork pattern (Fig. 1). In the nodular plaques the collagen showed a whorled pattern while sections parallel to the

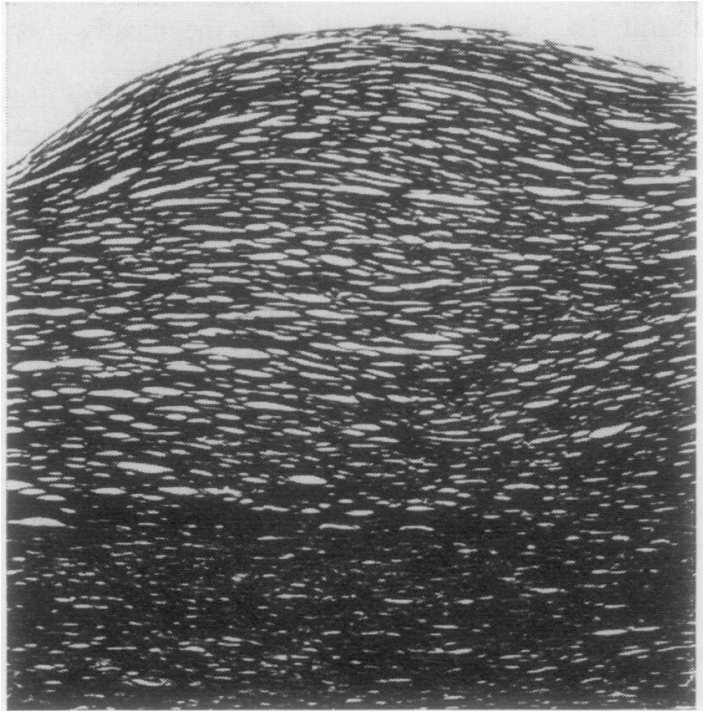

Fig. 1 Hyaline pleural plaque showing reticulated meshwork pattern. (Verhoeff-Van Gieson $\times 80$.)

surface of plaques showed a coarsely woven trabeculated pattern. When stained with Verhoeff's method for elastic fibres, counterstained with Van Gieson's solution (Culling, 1963), some plaques stained black as for elastic tissue rather than red for collagen (Fig. 1).

The plaques were relatively acellular and only an occasional spindle-shaped fibroblast could be identified (Fig. 2); focal areas of calcification showed either as fine particles or more massive areas (Fig. 3). In one case small amounts of fibrin were present on the surface of the plaques; none was covered with mesothelial cells, but a single layer of small cuboidal cells extended up to the margin of the plaques in some cases. In the fatty adipose tissue beneath the

Fig. 2 Reticulated pleural plaque showing spindle-shaped. fibroblasts. $($ H.E. $\times 240$.

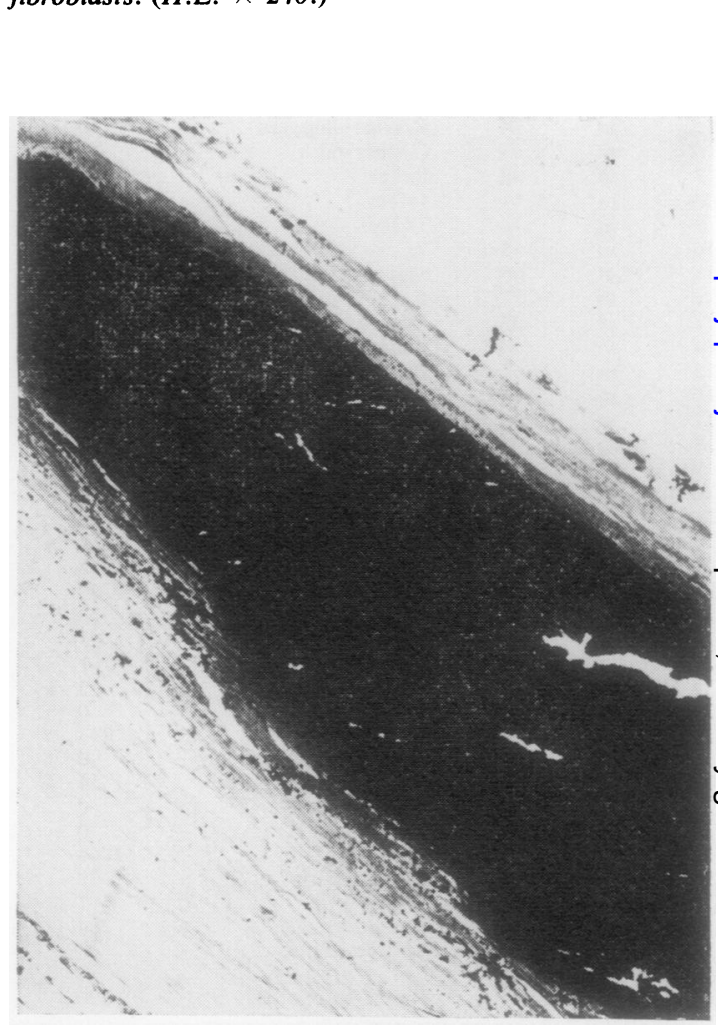

Fig. 3 Calcified pleural plaque. (Von Kossa $\times 200$.) 


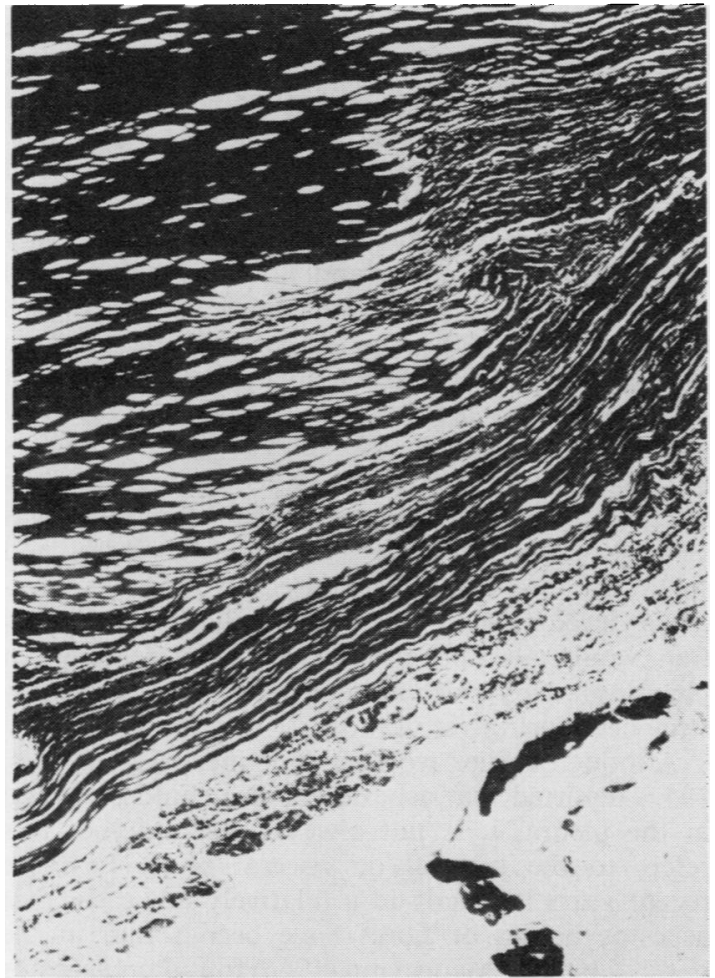

Fig. 4 Edge of pleural plaque showing connective tissue of pleura passing deep to the plaque. (Verhoeff-Van Gieson $\times 80$.

plaque dilated, congested vessels surrounded by variable numbers of lymphocytes and plasma cells were a constant finding. In no case were inflammatory cells present in the plaques.

The boundary between a plaque and the surrounding pleura was always sharply demarcated and the ordinary connective tissue of pleura could be identified passing deep to the plaque (Fig. 4).

No asbestos bodies were seen in any of the plaques sectioned at $5 \mu$ and $25 \mu$; in two cases scanty but typical bodies were found by the extraction technique.

Histological evidence of minimal basal asbestosis was found in seven of the 28 cases $(25.0 \%)$.

\section{Discussion}

The results support the causal relationship between hyaline parietal pleural plaques and exposure to asbestos based on radiological examinations during life, and on necropsy findings (Kiviluoto, 1960; Lawson, 1963; Hourihane et al, 1966; Meurmann, 1966; Anton, 1967 and 1968). Plaques were found in 41 of 334 necropsies $(12.3 \%)$ which is close to the findings at the London Hospital $(11.2 \%$ of 134 necropsies) (Hourihane et al, 1966). Both these figures are considerably lower than the findings of Meurmann (1966) in Finland where plaques were found in $39.3 \%$ of 438 consecutive necropsies; a higher incidence of asbestos bodies was also found in the necropsies in Finland $(57.6 \%$ as compared to $24.3 \%$ and $30.8 \%$ in London and Glasgow respectively).

Plaques, like asbestos bodies, were commoner in males. Of the 41 cases in the present series only one was a female, a 'retired factory worker' of 68 years, who died from a carcinoma of the vulva; one asbestos body was found in the basal smears. Meurmann (1966) found that of 119 cases showing bilateral plaques, 85 were in males $(61.1 \%)$ whereas Hourihane et al (1966) found that $75 \%$ of his 56 cases were males.

There is a statistically significant difference in the incidence of pleural plaques in cases with and without asbestos bodies in the smears. Asbestos bodies were found in the smears from 35 of the 41 cases $(85.3 \%)$, as against Meurmann's (1966) percentage of 79 and the $100 \%$ of Hourihane et al (1966).

In six cases $(14.7 \%)$ no asbestos bodies were found in the basal smears; Meurmann (1966) was unable to find asbestos bodies in approximately $20 \%$ of the cases showing plaques, even when up to 10 sections were examined from different parts of the lung. In none of the six cases of plaques but without asbestos bodies in the present series was there evidence of pulmonary tuberculosis, which is a recognized cause of pleural plaque formation, especially if unilateral (Hourihane et al, 1966). Neither was there evidence in the clinical histories or in the necropsy findings that these plaques were the result of calcified haemothoraces. It may be that although exposure to asbestos is the commonest cause of pleural plaques, there still exist unidentified causes.

There seems to be a relationship between the incidence of plaques and the number of asbestos bodies found in the lungs, and that plaques are more likely to be found if asbestos bodies are numerous, suggesting that there is a 'dose-response' relationship (Hourihane and McCaughey, 1966). Of 57 cases in which less than five bodies were counted, plaques were found in nine $(15.8 \%)$; plaques were present in $32.6 \%$ of 52 cases where five to 50 bodies were found. In eight cases where more than 100 asbestos bodies were counted pleural plaques were present in all. Hourihane and McCaughey (1966) suggested that the dosage of asbestos related to the number of pleural plaques is of a size between that necessary for the development of mesothelioma in the general population in whom small amounts of 
asbestos will be found in the lungs, and classical asbestosis in subjects with large amounts of asbestos in the lungs, a history of industrial exposure, and an increased incidence of mesothelioma.

Plaques were found posteriorly in the lower half of the pleural cavities, in the paravertebral fossae, and on the diaphragm. In none of the cases were plaques found at the apices, in the costophrenic angles, or on the anterior wall close to the costochondral junctions. This selective distribution within the pleural cavities was also observed by Meurmann (1966), who suggested that mechanical factors were involved, possibly the varying pressures and stretching to which the pleura is subjected during respiration. Fibrous adhesions which would restrict free respiratory movement might be expected to hinder the formation of plaques; thus in three cases showing plaques on the costal pleura the other pleural space was obliterated by fibrous adhesions and was clear of plaques. Meurmann (1966) also commented that plaques occurred in areas of pleural surface which were free of adhesions.

The mechanism by which asbestos induces the formation of plaques is uncertain, and histological examination does little to resolve this uncertainty. Kiviluoto (1960) suggested that the sharp points of asbestos fibres protrude through the visceral pleura into the pleural cavity. During respiration the parietal and visceral layers rub against each other and the points of the asbestos fibres have an abrasive action on the parietal pleura which leads to a slight but continuously produced fibrinous exudation. Subsequently, fibrous organization takes place and poor nourishment at the centre of the plaques leads to degenerative changes followed by calcification. Similarly Siegal, Smith, and Greenburg (1943) suggested that mechanical factors combined with haemorrhage as a possible explanation; it was suggested that small particles caused small pulmonary and pleural haemorrhages which subsequently calcified as larger haemothoraces are known to do.

Histologically all the plaques in the present series were composed of relatively acellular bands of laminated collagen, and, although lymphocytes and plasma cells were seen in the fatty tissue beneath plaques, no evidence of an inflammatory exudate or granulation tissue was seen within plaques. Neither was haemosiderin identified as would be expected if pleural haemorrhage had played an important part in their formation (Siegal et al, 1943). Only in one case was there a small amount of fibrin on the surface of a plaque. Hourihane et al (1966) found fibrin incorporated into the surface layer of a plaque in only one of 50 cases, and Meurmann saw no fibrinous exudation in 172 cases.
Pleural plaques stained black as for elastic in the Verhoeff-Van Gieson method (Culling, 1963); Gillmann, Penn, Bronks, and Roux (1955) described such 'pseudo elastic fibres' in skin scars, gallbladders, $\stackrel{\oplus}{+}$ and arteries and suggested that they were derived from alteration in the composition of preformed $\underline{\underline{E}}$ collagen. These pseudo-elastic fibres were frequently? calcified, and Gillmann and his colleagues (1955) suggested that this was an aging process. Thises might be an explanation for calcification in someplaques and an alternative to the suggestion that:calcification is a degenerative change as a result of $\vec{\omega}$ poor nourishment at the centres of the plaques 2 (Kiviluoto, 1960). Spencer (1963) found that theo fibrous tissue of a pulmonary scar carcinoma wasi also composed of these pseudo-elastic fibres, and suggested that collagen exposed to repeated stret- $\omega$ ching develops elastic properties. Such an explana-co tion would account for the tinctorial reaction in음 pleural plaques which are constantly and repeatedly stretched during respiration.

Although earlier workers (Gloyne, 1933; Wyers, 1949) reported that asbestos bodies could be found $\vec{\theta}$ in the pleura, it is not always clear whether this - refers to the parietal or visceral layer. In more recent years it is only in a relatively few cases that asbestos bodies or fibres have been found in the parietal pleura. Meurmann (1966) found no asbestos. bodies or fibres in sections of 172 plaques despite the use of polarized light. Hourihane et al (1966) found asbestos fibres in four of 12 cases using a을 technique of maceration and phase-contrast micro- $\frac{3}{2}$ scopy. In the present 28 cases scanty asbestos bodies were revealed in two by the extraction techniques(Gold and Kerr, 1967).

That asbestos fibres or bodies have been detected:in so few parietal plaques suggests that the presence 3 . of these foreign bodies is not necessary to produce plaques.

I wish to thank Mr G. F. Headden, FIMLT, for the photomicrographs.

References

Anjilvel, L., and Thurlbeck, W. M. (1966). The incidence of asbestos bodies in the lungs at random necropsies in Montreal. Canad.W med. Ass. J., 95, 1179-1182.

Anton, H. C. (1967). Multiple pleural plaques. Brit. J. Rodial., 40, 685-690.

Anton, H. C. (1968). Multiple pleural plaques, Part II. Brit. J. Radiol., $\frac{\mathrm{C}}{\mathrm{D}}$ 41, 341-348.

Ashcroft, T. (1968). Asbestos bodies in routine necropsies on Tyneside $\stackrel{\text { ( ) }}{:}$ a pathological and social study. Brit. med. J., 1, 614-618.

Cauna, D., Totten, R. S., and Gross, P. (1965). Asbestos bodies ino human lungs at autopsy. J. Amer. med. Ass., 192, 371-373.

Cooke, W. E. (1927). Pulmonary asbestosis. Brit. med.J., 2, 1024-1025.

Culling, C. F. A. (1963). Handbook of Histopathological Techniques, $\mathbb{D}$ 2nd ed., p. 342. Butterworth, London.

Gillman, T., Penn, J., Bronks, D., and Roux, M. (1955). Abnormalర elastic fibres. Appearances in cutaneous carcinoma, irradiation 
injuries and arterial and other degenerative connective tissue lesions in man. Arch. Path., 59, 733-749.

Gloyne, S. R. (1933). The morbid anatomy and histology of asbestosis. Tubercle (Edinb.), 14, 550-558.

Gloyne, S. R. (1935). Two cases of squamous carcinoma of the lung occurring in asbestosis. Tubercle (Edinb.), 17, 5-10.

Gold, C., and Kerr, A. W. (1967). A simple method for detecting asbestos in tissue. (Abstr.,) J. clin. Path., 20, 674.

Hourihane, D. O'B., Lessof, L., and Richardson, P. C. (1966). Hyaline and calcified pleural plaques as an index of exposure to asbestos. A study of radiological and pathological features of 100 cases with a consideration of epidemiology. Brit. med.J., 1, 1069-1074

Hourihane, D. O'B., and McCaughey, W. T. E. (1966). Pathological aspects of asbestosis. Postgrad. med. J., 42, 613-622.

Kiviluoto, R. (1960). Pleural calcification as a roentgenologic sign of non-occupational endemic anthrophyllite-asbestosis. Acta radiol. (Stockh.), Suppl. 194.

Lawson, J. P. (1963). Pleural calcification as a sign of asbestosis: a report of three cases. Clin. Radiol., 14, 414-417.

Lynch, K. M., and Smith, W. A. (1935). Pulmonary asbestosis. III. Carcinoma of lung in asbestos-silicosis. Amer. J. Cancer, 24, 56-64.
Meurmann, L. (1966). Asbestos bodies and pleural plaques in a Finnish series of autopsy cases. Acta path. microbiol. scand., Suppl., 181.

Oliver, T. (1927). Clinical aspects of pulmonary asbestosis. Brit. med. J., 2, 1026-1027.

Roberts, G. H. (1967). Asbestos bodies in lungs at necropsy. J. clin. Path., 20, 570-573.

Roberts, G. H. (1969). MD Thesis, University of Wales. Necropsy studies of asbestos bodies in Glasgow and a clinico-pathological study of pleural mesothelioma.

Siegal, W., Smith, A. R., and Greenburg, L. (1943). The dust hazard in tremolite talc mining including roentgenological findings in talc workers. Amer. J. Roentgenol., 49, 11-29.

Spencer, H. (1963). Pathology of the Lung, p. 645. Pergamon, Oxford. Stewart, M. J., Tattersall, N., and Haddow, A. C. (1932). On the occurrence of clumps of asbestos bodies in the sputum of asbestos workers. J. Path. Bact., 35, 737-741.

Thomson, J. G., and Graves, W. M. Jr. (1966). Asbestos as an urban air contaminant. Arch. Path., 89, 458-464.

Thomson, J. G., Kaschula, R. O. C., and MaDdonald, R. R. (1963). Asbestos as a modern urban hazard. S. Afr. med. J., 37, 77-81.

Wyers, H. (1949). Asbestosis. Postgrad. med. J., 25, 631-638.

\section{The April 1971 Issue}

The interpretation of the serum protein-bound iodine: A review J. D. ACLAND

Value of plasma chloride concentration and acid-base status in the differential diagnosis of hyperparathyroidism from other causes of hypercalcaemia $\mathbf{M}$. $\mathbf{R}$. WILLS

Enzymatic and immunochemical determination of plasminogen and plasmin in different physiological and pathological states P. M. MANNUCCI, R. STABILINI, R. BRAGOTTI, BIANCA MARASINI, AND A. AGOSTONI

Relationship between total body water and surface area in normal and obese subjects R. HUME AND ELSPETH WEYERS

Effect of $p \mathrm{H}$ changes on the binding of vitamin $\mathrm{B}_{12}$ by intrinsic factor HING-YAN SHUM, BARRY J. O'NEILL, AND ARTHUR M. STREETER

Diagnostic value of the serum folate assay $\mathrm{J}$. FORSHAW AND LILIAN HARWOOD

An assessment of platelet aggregation induced by 5-hydroxytryptamine BARBARA P. HILTON AND J. N. CUMINGS

Part I After pre-incubation with 5-hydroxytryptamine and reserpine. Part II In plasma from control subjects and migraine sufferers in relation to methysergide, St155, and tyramine
Use of plasma instead of serum in laboratory tests for infectious mononucleosis R. J. L. DAVIDSON AND S. R. MAIN

Endocardial fibroelastosis in children with special reference to the lesions of cardiac ganglia ALBINA żóŁTOWSKA

Structure and ultrastructure of the labial salivary glands in patients with cystic fibrosis R. G. DOGGETT, B. BENTINCK, AND G. M. HARRISON

\section{Technical methods}

New methods applied to the identification of glycogen in pathological material L. B. MURGATROYD

A dextran slide test for blood grouping D. I. $\mathbf{K}$. EVANS

A quick method for reading the indirect haemagglutination test BRIDGET G. WOODHEAD AND D. S. RIDLEY

\section{Present day prastice}

Antibiotics in mycoplasma media and the temporary storage of specimens containing mycoplasmas of the genital tract C. S. GOODWIN, M. C. COWAN, AND D. J. LAVIS

Book reviews

Copies are still available and may be obtained from the PUBLISHING MANAGER, BRITISH MEDICAL ASSOCIATION, TAVISTOCK SQUARE, WC1H 9JR price $£ 1.05$ 